Supplement of SOIL, 3, 95-112, 2017

http://www.soil-journal.net/3/95/2017/

doi:10.5194/soil-3-95-2017-supplement

(C) Author(s) 2017. CC Attribution 3.0 License.

(c) (i)

Supplement of

\title{
Nitrate retention capacity of milldam-impacted legacy sediments and relict
} A horizon soils

Julie N. Weitzman and Jason P. Kaye

Correspondence to: Julie N. Weitzman (julie.weitzman@asrc.cuny.edu)

The copyright of individual parts of the supplement might differ from the CC-BY 3.0 licence. 


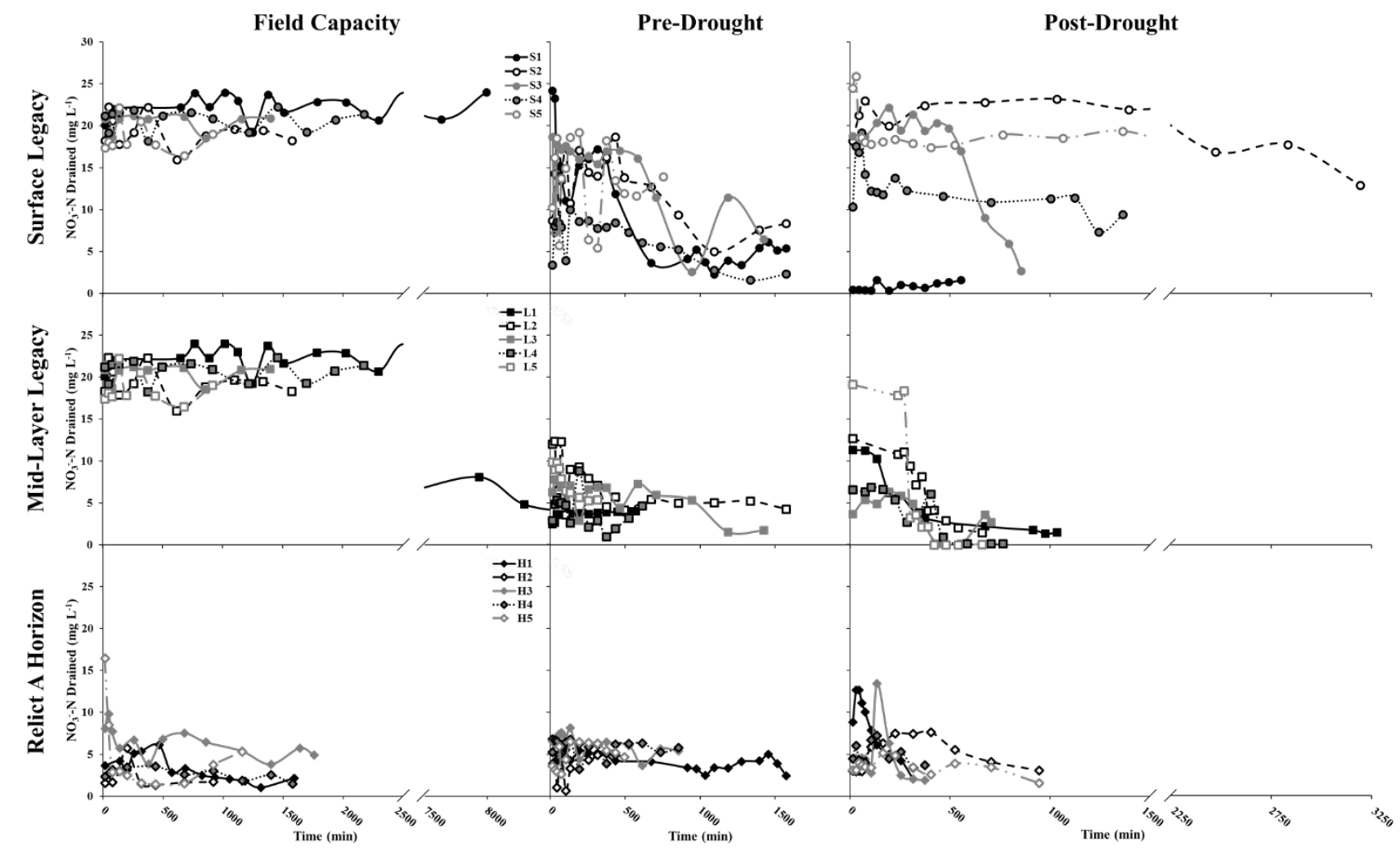

Supplementary Figure S1. Time series release curves depicting the release of leachate $\mathrm{NO}_{3}{ }^{-}$over time for each of the five replicate soil columns from each of the three soil horizons of interest (surface legacy sediment, mid-layer legacy sediment, and relict A horizon soil) during field capacity, pre-drought, and post-drought conditions. 